\title{
Understanding emotionally relevant situations in primary dental practice. 2. Reported effects of emotionally charged situations
}

Helen R. Chapman $(1,2)$ MSc, BDS

Susan Y. Chipchase (3) BSc, MSc, PhD

Roger Bretherton (4) BSc, DClinPsy

1. Paul Lowe Dentistry, 31 Farmhouse Way, Monkspath, Solihull B90 4EH

2. Visiting Fellow, School of Psychology, University of Lincoln, Brayford Pool, Lincoln LN6 7TS

3. Senior Lecturer, School of Psychology, University of Lincoln, Brayford Pool, Lincoln LN6 7TS

4. Senior Lecturer, School of Psychology, University of Lincoln, Brayford Pool, Lincoln LN6 7TS

${ }^{*}$ Correspondence to: Mrs Helen Chapman email:

hchapman@lincoln.ac.uk 


\section{ABSTRACT}

Background and Aims: Dentistry is widely reported to be a stressful profession. There is a limited body of research relating to the coping strategies used by dentists whilst in clinical situations. This study aims to use qualitative methods to explore the full extent of the coping strategies associated with stressful events in primary dental practice. Method:

Semi-structured interviews were conducted with 20 dentists within a 50 mile radius of Lincoln. A thematic analysis was conducted on verbatim transcriptions thereby identifying 6 Themes and 35 codes. Results: Participants described both problem-focussed and emotion-focussed strategies. The strategies used had a variety of outcomes in the context of use. Most dentists denied that their emotions affected their decision making, but then proceeded to describe how they were influential.

Discussion and Conclusion: Dentists use a wide variety of coping strategies some of which are maladaptive. Training in the development and recognition of appropriate coping decisions would be appropriate as they would, potentially, improve practitioner decision making and wellbeing.

Key words Dentists' stress; Coping

1. Describes the effects of occupational stress on dentists

2. Describes the coping strategies used by dentists in difficult clinical situations

3. Discusses the implications of dentists' psychological well-being 


\section{INTRODUCTION}

Coping strategies have been defined ${ }^{1}$ as "constantly changing cognitive and behavioural efforts to manage specific external and /or internal demands that are appraised as taxing or exceeding the resources of the person." (p141) They may be categorised by intended function; to manage the situation (problem-focused) or the level of emotional distress (emotion-focused). Thus the coping strategies used may be grouped as a matrix; problem- or emotion-focused and behavioural or cognitive strategies. Lazarus and Folkman ${ }^{1}$ acknowledged that the outcome of the use of coping strategies may be either negative or positive. Carver et al. ${ }^{2}$ further analysed coping strategies, grouping them, broadly into problem-focused, emotion-focused strategies, and "less useful" strategies. Yet other researchers categorised other strategies. ${ }^{3}$ (Table 1) Current research suggests that the use of coping strategies such as positive reappraisal and planful problem solving can help to buffer stress ${ }^{4}$ and are associated with an increase in positive emotional experience, thereby building resilience. ${ }^{56}$ Strategies such as emotional suppression and rumination increase the experience of negative emotions such as anxiety. .;3 $^{2}$

A number of questionnaire-based studies have considered the nature of the stressors present in primary care dental practice. ${ }^{7}$ In general, the exploration of dentists' coping ${ }^{8}$ has been basic, with generic, trait coping strategies being explored. A single study ${ }^{9}$ has found that dentists self-report a perceived inability to cope with many commonly experienced stressors. The current authors are unaware of any research exploring any unique stressors of being a Foundation Dentist (DF1). (Foundation dentists are newly qualified and work in approved primary care general dental practices with a mentor/clinical trainer who is an experienced dentist) The need to teach dental students coping skills before graduation has been recognised ${ }^{10}$ and attempted. ${ }^{11}$

Flexibility in coping is associated with greater well-being ${ }^{1}$ and achievement and negatively associated with stress reactions, alienation (feeling mistreated and experiencing bad luck) ${ }^{12}$ and lower levels of burnout. ${ }^{13}$ The stress of hiding one's emotions in the dental surgery has been linked to an increase in adverse clinical events. ${ }^{14}$ Apart from this, the current authors are unaware of any research which assesses the impact of stress on clinical performance in dentists. These facts have implications for patient care as well as dentists' well-being.

Self-reported coping strategies using checklists have been criticised as 1 . recall can be unreliable; 2 . the meaning of a particular coping strategy can change depending on when in relation to the event it occurs. ${ }^{15} 3$. they fail to reveal the transactional and interpersonal nature of coping, ${ }^{16} 4$. they tend to measure trait rather than state coping $^{17}$ and therefore lose the context of specific events and the ability to reflect any flexibility in coping style. This limits the usefulness of the data in understanding the coping process.

Narrative methods elicit ways of coping which are not mentioned on checklists. However, some ways of coping may be omitted without the prompting of the list. ${ }^{18}$ This method also allows for an exploration of the meaning of the event, the 
contextual factors which may influence coping as particular situations evolve and may reveal new perspectives on the area of inquiry. ${ }^{19}$ Thematic analysis is a flexible, theoretically neutral approach to the analysis of this type of data. ${ }^{20}$

The aims of this study were to identify:

1. the negative emotions (including, but not exclusively, fear/anxiety) and positive emotions experienced by primary care dental practitioners (PCDPs) in the course of their clinical work

2. the nature of situations which elicited these emotions

3. the strategies dentists used to cope with the described situations

4. the effect that dentists believed these emotions had on their clinical decision making.

This study formed part of a series, with a subsequent quantitative study ${ }^{21}$ exploring the relationship between anxiety-provoking situations and decision-making, and the development and evaluation of a coping skills package.

This paper presents the data relating to the effects (for example physiological) of the positive and negative situations on the dentists and the various coping strategies which the dentists described as using in order to address the problem or to control their emotional response. (Aim 4) These include any reported effects on their clinical decision making. (Aim 3) The use of semi-structured interviews allows the context, functionality and consequences to the considered. A previous paper ${ }^{22}$ presented the data relating to the nature of the emotions experienced by dentists and the difficult situations which provoked them. A subsequent paper ${ }^{23}$ explores the transactional nature of stress experienced by PCDPS.

\section{METHOD}

A detailed methodology is described in a previous paper. ${ }^{22}$ The interview schedule is presented in Box 1.

\section{Participants}

Primary dental care practitioners within a 50 mile radius of the University of Lincoln were contacted via BDA section secretaries, editorial features in the dental press and 'snowballing'. ${ }^{24}$ Twenty five eligible dentists responded and 20 were chosen to were chosen to participate so as to ensure a purposive sample with regard to type of practice (general dental practice [NHS, mixed or private]; community dental service [CDS]; dental foundation trainees [DF1]), date of qualification and location (urban; suburban; rural). These dentists were contacted by telephone and hour-long interviews arranged at their practice.

\section{Procedure}

Ethical approval was obtained from the University of Lincoln, School of Psychology Ethics Committee. During February-June 2011, semi-structured interviews were conducted by SC, recorded and transcribed verbatim. They were then analysed and coded by HC. The developed codes were organised into overarching themes. This was reviewed by SC and RB. Representative quotes were chosen by the 3 researchers. A detailed description of the analysis appears in a previous paper. ${ }^{22}$ 


\section{RESULTS \\ Demographics}

Of the 20 dentists interviewed, 11 were female (55\%); seventeen were in general dental practice, 6 of whom were dental foundation (DF1) dentists, and three worked for the Community Dental Services (CDS). The mean year of qualification was 1993 (range 1966 - 2011) with a mean number of years in primary dental care practice of 17.3 (SD 13.23; range 1-46). Full details were given previously. ${ }^{22}$

\section{Thematic analysis}

The thematic analysis produced a total of 36 codes over 6 themes. Themes 1-3 (Codes 1-27) relating to dentists' expressed emotions, negative and positive situations, have been reported previously. ${ }^{22}$ This paper reports the Theme 4 (physiological and mental effects on the dentists - Codes $27 \& 28$ ) and Theme 5 which describes the resultant strategies used by dentists (Codes 29 - 34) and a miscellaneous category (Code 35). Theme 6 (Code 36) related to information not relevant to the analysis. The coding for the thematic data developed during the iterative process of analysis, the details of which are set out in a previous paper. ${ }^{22}$ It became apparent that a stress-coping model ${ }^{1}$ would be an appropriate framework within which to contextualise the inductively derived findings.

Once dentists had described a difficult situation, a variety of probes were used to establish any responses used to manage the emotional situation and how the emotion affected the dentist.

\section{Responses to difficult clinical situations}

Dentists reported a very wide range of responses to emotionally salient clinical situations. Many of these were only reported once, by a single dentist, in response to a particular situation. Others were more widely reported.

Whilst physiological and automatic cognitive responses were beyond the dentists' conscious control, they took a variety of actions to consciously attempt to control difficult situations. These could be grouped as behaviours intended to manage the situation (Code 30); behaviours intended to manage the emotion (Code 31), mental processes aimed at managing the situation (Code 32) and mental processes used to manage the emotion (Code 33), thus fitting with the well-stablished model of Lazarus and Folkman. ${ }^{1}$ Responses in any of these codes could improve the situation or cause it to (potentially) deteriorate; in other words be functional or dysfunctional.

\section{Effects internal to the dentist (Theme 4)}

\section{Physiological responses (Code 28)}

Only a few dentists made reference to their physiological responses to clinical situations. These were the classic signs of sympathetic arousal. 'you start to sweat ... to shake' [1:41]

\section{Mental responses (Code 29)}

In response to difficult situations, dentists reported a series of unconscious thinking patterns, all of which were unhelpful. These are different to the mental processes 
which are used to attempt to manage the situation or emotion and included personalisation, catastrophising, mind reading and wishful thinking.

'I want a hassle free existence really I do.' [17:39]

Many dentists believed that they can or should be able to change their patients' behaviour, leading to feelings of frustration.

'Anger to a mild degree with regard to those patients that are ... not just able bodied but also have the capacity to understand the consequences of dental disease and don't actively do much about it even though we give them advice over and over again.' [16:74]

\section{Resultant Coping Strategies (Theme 5)}

Negative emotionally loaded events provoked the use of a wide range of strategies. These could be grouped into behaviours and mental (cognitive) processes. All were used with the aim of directly managing the situation and thus reducing the experienced emotion indirectly or directly. Dentists did not try and control their, less intense, positive emotions.

\section{a) Behaviours to manage the situation (Code 30)}

This was the largest group of strategies used by dentists. They were often the result of conscious, planned decisions.

The majority of dentists said that 'The anxiety didn't make much difference in that situation' [3:7] but would then go on to describe situations where the emotion had had an impact on the treatment or treatment planning, for example proceeding more slowly, being driven to take shortcuts by lack of time, splitting treatment and reappointing to complete it, trying to modify unrealistic patient expectations.

'I could feel myself getting frustrated and it did make me not take any more teeth out.' [18:8]

Several dentists reported controlling anxiety by preparation or by having a plan of action.

'I'd read up on the procedure.' [2:25]

All the dentists reported that their longer term coping involved filling in gaps in their education by shadowing, working under supervision or attending CPD courses. 'I ask to be able to do that kind of work in a different environment under supervision,' [16:21]

Seeking social support from colleagues and, if appropriate, family was a universal strategy. It functioned to provide (1) valuable practical clinical support at the time of the difficulty and (2) a debriefing which might be totally informal or more formal. I would raise it in peer review with my colleagues, so they would give feedback.' [4:17] However, recently qualified dentists (DF1s) sometimes found that emotional support from their trainers was lacking.

'It's more with the technical things that [my DF1 Trainer] or one of the other dentists gives me [help with]' [12:18], [10:20-21]

Depending on context, this type of coping also functioned to manage emotion (code 31). 
It was universally held that the support of a good nurse was important, helping both dentist and patient. They were viewed as crucial as witnesses to what had happened in difficult situations and were trusted to offer a debriefing.

'My nurse and I talked about it and thought the person was being unreasonable and we didn't feel that we could have managed it any better or any differently.' [21:43]

Referral was used to control situations which were accompanied by anxiety and anger group emotions. It took 3 basic forms:

- 'Please find another dentist.' This was often a result of a disagreement over treatment, especially where a lack of trust in the dentist's professional ability was implied. The accompanying emotion was frustration or frank anger.

'I was fuming all the way through that appointment. ... [I] finished it all off and they went and just told my receptionist I never wanted to see that person in my surgery again.

- Reactive referral occurred when something had gone wrong.

'I couldn't remove the tooth ... I had to refer him on elsewhere for someone to get the tooth out.' [20:4]

- Proactive referral was often based on knowing one's limitations as a result of learning from experience. The predominant emotion was anxiety.

'know [ing] what your comfort zone is, or ... what you can and you can't do so you may refer more appropriately.' [9:4]

It was also used when there was a disagreement about treatment planning and patient expectations were unlikely to be met.

'I didn't treat her, I referred her to someone else for treatment because the treatment that she wanted me to do, I wasn't happy to do, ... I said okay, we'll give you a second opinion.' [11:22]

It was important to maintain a good standard of polite communication, including apologies, and to be compassionate, especially when things got difficult.

'you'd ... be a little bit ... kinder or try and give them a bit more of your [time], be more tolerant to someone in a distressed time.' [4:76]

\section{b) Actions to manage the emotion (Code 31)}

Discussion with colleagues served to normalise difficult situations and offered a safe place to vent intense emotions 'just having a little rant just makes you feel a little bit better.' [18:11]

There was a general tendency to share happy situations less frequently than frustrations as this was viewed as 'showing off.'

'I wouldn't brag about what I've done.' [20:39]

Dentists adopted a variety of strategies to deal with their personal emotional responses to difficult situations and to patient anxiety and difficult behaviours. These included stopping the emotional vicious circles described in an earlier paper. ${ }^{22} \mathrm{An}$ almost universal strategy was to not let the patient know one was anxious, disgusted or frustrated by trying to appear calm, in control, confident and professional and by paying attention to nonverbal communication style. This was aided by wearing a physical mask or, more often, a metaphorical mask 'which must never slip' and, above all, smiling. Happy emotions were hidden by a small minority of subjects. 'You learn to hide what you don't want people to see.' [1:19]

'I just mask it and smile.' [5:6] 
It was considered acceptable to 'express ... regret and concern for [the patient]' [4:78] if things did not go to plan.

Dentists used viewing the daylist in 2 diametrically opposite ways as a means of reducing anticipatory anxiety. They either didn't look at it so that they didn't worry, or they deliberately viewed it so that they could plan.

'I'd want to know if I had anything that I felt was difficult coming in or that might be a bit challenging.' [19:40]

High levels of difficult emotions provoked some form of separation or distancing from the patient. Dentists would choose to escape by leaving the room, often taking the opportunity to vent (usually) frustration.

'try[ing] and get into a different situation, into a different room and drink water or go outside or do whatever I can to just run away from the situation.' [3:93]

Space from patients was created within the surgery in a variety of ways: by taking a breath, sending the patient back to the waiting room, falling back on reviewing the clinical situation (for example, viewing x-rays) or, quite commonly, by 'zoning out'. 'counting to ten' [4:24];

'just trying to zone myself out.'[18:10]

The use of alcohol was touched on by two dentists, with immediate denial of problems and exercise /sport was used as a way of 'burning off stresses or as a distraction by several dentists.

'if you're trying to play golf your focused on a little ball you're not focused about Mrs Bloggs who you know might be in tomorrow morning.' [17:67]

\section{c) Mental processes to manage the situation (Code 32)}

The conscious cognitive strategies used by dentists included treatment planning and reflection to deal with clinical situations and drawing on personal or vicarious experience to increase empathy for patients.

'I think of a plan of what I'm going to say or do or just look through the notes, check we haven't missed anything.' [9:26]

Other attempts to solve the problem were less helpful.

'the shortcuts become the only thing that you can think of in that situation rather than doing what's right you just think, what's going to solve ... the immediate problem.' [3:53]

Retrospective reflection was often used to assess outcomes and dentists reported that learning from experience was associated with reduced anxiety.

'next time you come across that situation, you feel better prepared in your own self to deal with it.' [18:41]

\section{d) Mental processes to manage emotion (Code 33)}

These were consciously used strategies and included the use of unhelpful patterns such as rumination.

'I play it over and over in my mind as to how I should have dealt with the situation differently or what should happen.' [18:30]

Hypervigilance for threat was universal amongst dentists in the hope of preventing problems.

Chapman et al BDJ 2015 29(9) E8 Understanding emotionally relevant situations in primary dental practice. 2. Reported effects of emotionally charged situations 
'You think l'll follow the rules..., my training, ... and what you're supposed to do in these circumstances and then if it happens, if you go in front of a barrister and you say I did everything by the book but this happened anyway, because you always have that at the back of your mind [that] if you're doing anything and anything goes amiss, what will you say to the barrister?' [14:38]

More constructive techniques were reported by fewer dentists. These included cognitive reappraisal, using emotion as information, humour, self- instruction, selfreassurance.

'So if alarm bells are ringing for whatever reason ... I would say, ... it might be sensible to get someone else.' [16:43]

Difficult, emotionally provoking situations such as patient anxiety, difficult clinical situations or dentist frustration tended to be dealt with using a variety of psychological 'tricks'. Some used a reduced level of communication, others compartmentalised the situation.

'five o'clock switch my brain off from dentistry and forget all about it for the rest of the night.' [5:31]

For some compartmentalisation was achieved by focusing on the clinical.

'It's almost like partitioning your brain.' [1:20]

For others this extended to almost treating the patient as an object;

'There's [a] big sheet of glass between me and the patients ... so l'm unattached.' [8:42]

Boredom was associated with shifting to automatic pilot.

'a patient comes in and out and you've got no memory really whatsoever of them. You've zoomed out ...and you've probably switched off at some point and you're just ... on automatic ....' [19:72-3]

\section{e) Miscellaneous (Code 34)}

A variety of general issues arose across dentists and situations.

Some dentists denied doing anything specific to cope whilst others had unrecognised strategies.

'Just concentrating on all the clinical guidelines ... following all the protocols and making sure you're abiding by them ... But it's not a coping strategy, It's what you have to do anyway'. [14:46]

Almost all the experienced dentists noted that situations improved with experience. 'As l've got older l've got better at [dealing with] it.' [17:56]

Many of the dentists described personal characteristics or individual differences which they believed accounted for some of their behaviour. These were usually idiosyncratic.

'I suppose a lot of it depends on the personality of the dentist as to how well they cope with it.' [19:70] 'I'm a bit of chicken.' [22:26] 


\section{DISCUSSION}

This group of PCDPs showed a variety of positive and negative emotional responses to the reported clinical situations. These emotions resulted in a number of effects both on the dentist him/herself and the use of coping strategies; a pattern which is consistent with the coping skills model described by Lazarus and Folkman. ${ }^{1}$

Almost all the dentists reported that their emotional responses to difficult situations did not affect their clinical decision making, but then went on to describe what they had done to cope, which often impacted on the clinical situation. However, very few dentists commented on the type of routine decision where mild anxiety about the evolving situation would prompt modification of a treatment plan, for example, anxiety about exposing the pulp in a deeper than expected cavity prompting the dressing of the tooth. This may well be 1 . because dentists make these decisions instinctively, without being consciously aware of what prompted the change; 2 . because of a lack of recognition of what had happened or 3. owing to a reluctance to disclose this to the interviewer, possibly feeling that this would reflect badly on them. ${ }^{25}$ It might also have been that dentists understood the phrase 'decision making' in an idiosyncratic way;

'So it might affect the planning of treatment but, in essence, it wouldn't change my decision-making as to what was needed.' [21:26]

The non-dentally trained interviewer would not have known to prompt for these issues. It might be that PCDPs would be happier to disclose a change in treatment planning if the question were posed in the anonymity of a survey ${ }^{26}$ or to a fellow dentist.

Of the effects on the dentists in person, the nonconscious (cognitive) effects fitted with types of unhelpful cognitive thinking patterns (negative automatic thoughts) as described in the cognitive-behavioural therapy (CBT) literature ${ }^{27}$. The hypervigilance to threat described is associated with increased physiological arousal, increased attention to non-relevant threat, which then act as distractors, and may form a feedforward loop ${ }^{28 ; 29}$ and might impact on patient care.

Patients' lack of motivation with regards to self-care, despite the dentists' best efforts at education and instruction, was a significant source of frustration for PCDPs However, believing one can change another's beliefs is an unhelpful cognitive error ${ }^{30}$ and implicitly denies the patient the right to make decisions as stated in the GDC Standards ${ }^{31}$ However, anxiety about future, possibly ill-informed comments about supervised neglect may underlie this frustration and represent part of the hypervigilience to threat described above.

The obligation to carry on treating patients, even when they have complained, is now stated in the GDC Standards. ${ }^{31}$ This implies, for example, that the referral of a patient with whom one cannot agree a realistic treatment plan, or who has complained, would appear to be unprofessional. However, continuing to treat a patient where there appears to be a lack of trust, may well leave the patient more vulnerable as the fear and stress provoked by the situation are likely to leave the dentist at increased risk of poor decision-making and clinical errors. ${ }^{32 ; 33}$ 
Very few dentists described a physiological response to stressful situations which is consistent with previous research findings. ${ }^{34}$ However, a relationship has been found between work stressors and other long-term indicators of cardiovascular health such as raised diastolic blood pressure and borderline/abnormal ECGs. ${ }^{35}$ This suggests that the detrimental effects of dental practice are low-grade and chronic and associated with triggering of the HPA axis. ${ }^{36}$

Dentists universally reported a far greater variety of adaptive problem-focused coping strategies than emotion-focused coping. The dentists used planful problem solving widely, which generally results in a reduction in negative emotion and increase in positive emotions, changes which have implications for resilience and positive well-being. ${ }^{5}$ The large number of avoidant, emotion-focused coping strategies used (for example, escaping the surgery and rumination) are generally unhelpful. ${ }^{37}$ Generally speaking, if a situation is amenable to problem-solving or control, the use of problem-focused coping is the more adaptive course of action. ${ }^{17}$ However, if the situation is beyond one's control, then the use of adaptive emotionalfocused coping strategies such as reappraisal and acceptance are appropriate to manage the distress. Above all, flexibility in coping is associated with greater wellbeing and achievement and negatively associated with stress reactions and alienation (feeling mistreated and experiencing bad luck). ${ }^{12}$

All dentists reported the professionally- required need to hide their emotions, often describing the process as 'acting' or 'wearing a[metaphorical] mask.' Others wore a smile in all circumstances. 'Emotional work/labour' is defined as the "requirement to display organisationally desired emotions." $(p 371)^{38}$ This results in emotional dissonance (the holding conflicting emotions - personally experienced and professionally required), ${ }^{39}$ which in turn results in the need for emotional suppression (the conscious inhibition of one's own emotional expressive behaviour while emotionally aroused). This is associated with 1. burnout in other healthcare workers; $38 ; 40$ 2. impairment of mental performance (memory and decision-making tasks); $;{ }^{41 ; 4} 3$. increased sympathetic activation of the cardiovascular system, ${ }^{43}$ whilst, experimentally, having no effect on the subjective experience of emotion. It is also associated with adverse outcomes in the dental surgery, ${ }^{14}$ probably due to the increased cognitive load required to suppress emotional expression. Dentists used zoning out from the patient and into the clinical work as a way of dealing with patient anxiety and difficult clinical situations. This may be a way of avoiding the emotional and cognitive demands of emotional dissonance.

Unfortunately, hiding one's negative emotions can lead to the significant underestimation of another's level of negative emotional experience and to the overestimation of other's positive emotional experience, but by less. ${ }^{44}$ This has implications for communication style and interpersonal understanding in the surgery. Also, dentists may not be completely effective at hiding their emotions as patients may well be able to 'read' the fleeting micro-expressions which occur before conscious control becomes effective. ${ }^{45}$ This area of non-verbal communication requires further research.

This suggests that prevention of 'difficult situations' would improve the experience for both patient and dentist and would also improve patient safety. Experimental

Chapman et al BDJ 2015 29(9) E8 Understanding emotionally relevant situations in primary dental practice. 2. Reported effects of emotionally charged situations 
evidence suggests that people who respond to an obviously difficult situation with a smile are perceived by observers as being more self-confident, but also 'above the situation', unemotional and 'cold' ie less warm or gentle ${ }^{46}$. There is evidence that patients don't like physicians to behave in a neutral way; they prefer a display of supportive emotions, in particular, reassurance and a lack of hostility. ${ }^{47}$ This suggests that a display of anxiety or irritation would not be valued by patients. This area of dentist-patient non-verbal communication and its impact on care has yet to be researched.

Not only did most dentists share their positive emotions less frequently, but a minority also had a tendency to hide them. This has been found to predict lower levels of well-being and depressive symptoms. ${ }^{48}$ Positive affectivity is associated with increased resilience. ${ }^{49}$

Occasional difficult situation were created by interactions with nurses and colleagues. However, the overwhelming role of the nurse and colleagues was perceived as highly supportive. This opinion is borne out by longitudinal research ${ }^{50}$ which found that social support (affective affirmation, confirmation and direct help) have a moderating effect between stressors and psychological dysfunctioning.

Many dentists felt that venting was a successful way to deal with anger. Unfortunately, the research evidence ${ }^{51}$ suggests that it is a counterproductive coping strategy and leads the person to subjectively feel better in that moment, but actually increases objective measures of anger in the longer term.

The results of this sample suggest that there are differences in coping, in particular with experience. 'Knowing one's limitations' - an attribute linked to the perception of lower stress levels - was previously endorsed by $54 \%$ of dentists (Ranked $5^{\text {th }}$ ) as an a attribute of being a good dentist. ${ }^{52}$ This is further highlighted by the fact that DF1s sometimes considered themselves to be poorly supported emotionally.

There may also be gender differences in coping which did not emerge in this study because of the scale, but were found in a larger, quantitative study of coping ${ }^{53}$ and may be confirmed by a later, quantitative study. ${ }^{21}$

\section{CONCLUSION}

The dentists interviewed reported using a wide variety of problem-focused and emotion-focused coping strategies in an effort to try and cope with emotionally difficult situations in the dental surgery. Many of these strategies, particularly the emotional-focused ones, were apparently dysfunctional.

The PCDPs also believed that difficult, emotionally arousing, situations did not alter their clinical decision making processes, although they then went on to describe how the way they coped did actually change their treatment of their patients. This has profound implications for patient care.

The results of this study suggest that there is a need for education and training for dentists in 1. 'stress management' and 2. the recognition of decision-making processes. Any stress management training should focus on reducing the reliance 
on inappropriate emotional-focused coping which can be detrimental in the clinical situation and on building psychological resilience.

\section{Acknowledgements}

The authors are indebted to the Shirley Glasstone Hughes Trust for funding this project and to the dentists who gave to generously of their precious time. They would also like to thank Dr Nima Moghaddam and the anonymous peer reviewers for their helpful comments on earlier drafts of this paper. 


\section{Reference List}

(1) Lazarus RS, Folkman S. Stress, Appraisal, and Coping. New York: Springer Publishing Company, 1984.

(2) Carver CS, Scheier MF, Weintraub JK. Assessing coping strategies: A theoretically based approach. J Pers Soc Psychol 1989 Feb;56(2):267-83.

(3) Aldao A, Nolen-Hoeksema S. The influence of context on the implementation of adaptive emotion regulation strategies. Behav Res Ther 2012 Aug;50(7-8):493-501.

(4) Folkman S, Moskowitz JT. Stress, positive emotion, and coping. Current Directions in Psychological Science 2000 Aug;9(4):115-8.

(5) Folkman S, Lazarus RS. Coping as a mediator of emotion. J Pers Soc Psychol 1988 Mar;54(3):466-75.

(6) Tugade MM, Fredrickson BL. Resilient individuals use positive emotions to bounce back from negative emotional experiences. J Pers Soc Psychol 2004 Feb;86(2):320-33.

(7) Gorter RC, Albrecht G, Hoogstraten J, Eijkman MA. Measuring work stress among Dutch dentists. Int Dent J 1999 Jun;49(3):144-52.

(8) Ayers KM, Thomson WM, Newton JT, Rich AM. Job stressors of New Zealand dentists and their coping strategies. Occup Med (Lond) 2008 Jun;58(4):275-81.

(9) Moller AT, Spangenberg JJ. Stress and coping amongst South African dentists in private practice. J Dent Assoc S Afr 1996 Jun;51(6):347-57.

(10) Elani HW, Allison PJ, Kumar RA, Mancini L, Lambrou A, Bedos C. A Systematic Review of Stress in Dental Students. Journal of Dental Education 2014 Feb 1;78(2):226-42.

(11) Shankarapillai R, Nair MA, George R. The effect of yoga in stress reduction for dental students performing their first periodontal surgery: A randomized controlled study. Int J Yoga 2012 Jan;5(1):48-51.

(12) Lester N, Smart L, Baum A. Measuring coping flexibility. Psychol Health 1994 Aug;9(6):40924.

(13) Doolittle BR, Windish DM, Seelig CB. Burnout, coping, and spirituality among internal medicine resident physicians. J Grad Med Educ 2013 Jun;5(2):257-61.

(14) Tsutsumi A, Umehara K, Ono H, Kawakami N. Types of psychosocial job demands and adverse events due to dental mismanagement: a cross sectional study. BMC Oral Health 2007;7:3.

(15) Legare F, Ratte S, Stacey D, Kryworuchko J, Gravel K, Graham ID, et al. Interventions for improving the adoption of shared decision making by healthcare professionals. Cochrane Database Syst Rev 2010;(5):CD006732.

(16) Taris TW, Bakker AB, Schaufeli WB, Stoffelsen J, van Dierendonck D. Job control and burnout across occupations. Psychological Reports 2005 Dec;97(3):955-61.

(17) Lazarus RS, Folkman S. Transactional theory and research on emotions and coping. European Journal of Personality 1987 Sep;1(3, Spec Issue):141-69. 
(18) Folkman S, Moskowitz JT. Coping: Pitfalls and promise. Annu Rev Psychol 2004 Feb;55:74574.

(19) Folkman S, Lazarus RS, Dunkel-Schetter C, DeLongis A, Gruen RJ. Dynamics of a stressful encounter: Cognitive appraisal, coping, and encounter outcomes. J Pers Soc Psychol 1986 May;50(5):992-1003.

(20) Braun V, Clarke V. Using thematic analysis in psychology. Qualitative Research in Psychology 2006;3(2):77-101.

(21) Chipchase SY, Chapman HR, Bretherton R. Dentists' decision-making style and anxiety about clinical decision-making. Br Dent J. In press 2015.

(22) Chapman HR, Chipchase SY, Bretherton R. Emotions in primary dental practice: a thematic analysis 1. Clinical Situations and Accompanying Emotions. Br Dent J 2014.

(23) Chapman HR, Chipchase SY, Bretherton R. Understanding emotionally relevant situations in primary dental care practice. 3. Developing narratives. Br Dent J 2015.

(24) Goodman LA. Snowball Sampling. The Annals of Mathematical Statistics 1961;1:148-63.

(25) Paulhus DL. Two-component models of socially desirable responding. J Pers Soc Psychol 1984 Mar;46(3):598-609.

(26) Schwarz N, Strack F, Hippler HJ, Bishop G. The impact of administration mode on response effects in survey measurement. Applied Cognitive Psychology 1991 May;5(3):193-212.

(27) Beck JS. Cognitive therapy: Basics and beyond. New York, NY US: Guilford Press, 1995.

(28) Kimble M, Boxwala M, Bean W, Maletsky K, Halper J, Spollen K, et al. The impact of hypervigilance: Evidence for a forward feedback loop. Journal of Anxiety Disorders 2014 Mar;28(2):241-5.

(29) Richards HJ, Benson V, Donnelly N, Hadwin JA. Exploring the function of selective attention and hypervigilance for threat in anxiety. Clinical Psychology Review 2014 Feb;34(1):1-13.

(30) O'Doherty KM. The Little Book of Thinking Errors. London: Cognitive Therapy Books, 2009.

(31) General Dental Council. Standards for the Dental Team. London: General Dental Council, 2013.

(32) Janis IL, Mann L. Decision Making. New York: The Free Press, 1977.

(33) Croskerry P, Abbass A, Wu AW. Emotional influences in patient safety. J Patient Saf 2010 Dec;6(4):199-205.

(34) Bilodeau LP, Moody JM, Rathbun JD, Kraut RA. Evaluation of ECG changes in dentists treating awake patients. Anesth Prog 1983 Nov;30(6):193-6.

(35) Cooper CL, Mallinger M, Kahn R. Identifying sources of occupational stress among dentists. Journal of Occupational Psychology 1978 Sep;51(3):227-34.

(36) Michaud K, Matheson K, Kelly O, Anisman H. Impact of stressors in a natural context on release of cortisol in healthy adult humans: a meta-analysis. Stress (Amsterdam, Netherlands) 2008 May;11(3):177-97.

(37) Aldao A, Nolen-Hoeksema S, Schweizer S. Emotion-regulation strategies across psychopathology: A meta-analytic review. Clinical Psychology Review 2010 Mar;30(2):21737.

Chapman et al BDJ 2015 29(9) E8 Understanding emotionally relevant situations in primary dental practice. 2. Reported effects of emotionally charged situations 
(38) Zapf D, Vogt C, Seifert C, Mertini H, Isic A. Emotion work as a source of stress: The concept and development of an instrument. European Journal of Work and Organizational Psychology 1999 Sep;8(3):371-400.

(39) Phillips B, Tan TTW, Julian C. The theoretical underpinnings of emotional dissonance: a framework and analysis of propositions. Journal of Services Marketing 2006 Nov;20(6/7):4718.

(40) Zapf D, Seifert C, Schmutte B, Mertini H, Holz M. Emotion work and job stressors and their effects on burnout. Psychol Health 2001;16(5):527-45.

(41) Richards JM, Gross JJ. Composure at any cost? The cognitive consequences of emotion suppression. Personality and Social Psychology Bulletin 1999 Aug;25(8):1033-44.

(42) Hulsheger UR, Schewe AF. On the costs and benefits of emotional labor: A meta-analysis of three decades of research. J Occup Health Psychol 2011 Jul;16(3):361-89.

(43) Gross JJ, Levenson RW. Hiding feelings: the acute effects of inhibiting negative and positive emotion. J Abnorm Psychol 1997 Feb;106(1):95-103.

(44) Jordan AH, Monin Bt, Dweck CS, Lovett BJ, John OP, Gross JJ. Misery has more company than people think: underestimating the prevalence of others' negative emotions. Personality \& Social Psychology Bulletin 2011 Jan;37(1):120-35.

(45) Ekman P. Emotions Revealed - Understanding Faces and Feelings. London: Phoenix, 2004.

(46) Hareli S, Hess U. What emotional reactions can tell us about the nature of others: An appraisal perspective on person perception. Cognition \& Emotion 2010 Jan;24(1):128-40.

(47) DiMatteo MR, Linn LS, Chang BL, Cope DW. Affect and neutrality in physician behavior: A study of patients' values and satisfaction. J Behav Med 1985 Dec;8(4):397-409.

(48) Mauss IB, Shallcross AJ, Troy AS, John OP, Ferrer E, Wilhelm FH, et al. Don't hide your happiness! Positive emotion dissociation, social connectedness, and psychological functioning. J Pers Soc Psychol 2011 Apr;100(4):738-48.

(49) Gloria CT, Faulk KE, Steinhardt MA. Positive affectivity predicts successful and unsuccessful adaptation to stress. Motivation and Emotion 13 A.D. Mar;37(1):185-93.

(50) Frese M. Social support as a moderator of the relationship between work stressors and psychological dysfunctioning: A longitudinal study with objective measures. J Occup Health Psychol 1999 Jul;4(3):179-92.

(51) Lohr JM, Olatunji BO, Baumeister RF, Bushman BJ. The psychology of anger venting and empirically supported alternatives that do no harm. The Scientific Review of Mental Health Practice: Objective Investigations of Controversial and Unorthodox Claims in Clinical Psychology, Psychiatry, and Social Work 2007;5(1):53-64.

(52) Chandarana PV, Hill KB. What makes a good dentist? A pilot study. Dent Update 2014 Mar;41(2):156-8, 160.

(53) Rankin JA, Harris MB. Comparison of stress and coping in male and female dentists. J Dent Pract Adm 1990 Oct;7(4):166-72. 